\title{
The Impact of Psychological Capital Towards Job Satisfaction During COVID-19 Pandemic (Case Study at Government Institution in Cilegon City, Indonesia)
}

\author{
Yumna Sabila and Hary Febriansyah
}

\section{ABSTRACT}

\begin{abstract}
This government institution is one of the public services that focus on women's empowerment, child protection, and government affairs in the field of population control and family planning. However, when the COVID-19 pandemic occurred the service offered is not worked as well as the service motto that has been set by the organization. Based on Government Performance Accountability Report 2020, the organization's performance has decreased because several program's strategic objectives have not met the predetermined targets. The problems that have been identified from the preliminary interview can be categorized into issues related to employee job satisfaction. The researcher suspects that job satisfaction can be one of several issues that can affect employee performance. Positive psychological capital has a significant relationship with employee performance and job satisfaction. Also, the four facets of psychological capital (hope, efficacy, optimism, and resilience) may be a better predictor of performance and satisfaction. The condition of employee psychological capital can have a positive or negative impact on job satisfaction, so in this research, the researcher will analyze the impact of psychological capital towards job satisfaction. The researcher using PCQ-24 by Luthans and Job Satisfaction Survey by Spector questionnaire to determine the condition of psychological capital and job satisfaction. After the data has been gathered, the author uses descriptive analysis to determine the condition of psychological capital and job satisfaction. Also, uses linear regression to determine the impact of psychological capital towards job satisfaction.
\end{abstract}

Keywords: Descriptive Analysis, Employee Performance, Government Institution, Job Satisfaction, Linear Regression, Psychological Capital.

\author{
Submitted : July 26, 2021 \\ Published : August 18, 2021 \\ ISSN: 2507-1076 \\ DOI: $10.24018 /$ ejbmr.2021.6.4.997 \\ Yumna Sabila* \\ Master of Business Administration, \\ Bandung Institute of Technology, \\ Bandung, West Java, Indonesia. \\ (e-mail: yumsabila@gmail.com) \\ Hary Febriansyah \\ Bandung Institute of Technology, \\ Bandung, West Java, Indonesia. \\ (e-mail: hary@sbm-itb.ac.id) \\ *Corresponding Author
}

\section{INTRODUCTION}

One of the capitals owned by each individual is Psychological Capital, where positive psychological capital encourages individuals to always confident to achieve their goals and successes, eager to reach targets and have a high level of satisfaction with their work. According to [1] psychological capital integrates the four HERO (Hope, SelfEfficacy, Resilience and Optimism) positive psychological resources that will help maintain an internalized sense of control and intentionality while goals are being pursued and accomplished. The four capacities of Psychological Capital are measurable, open to development and make performance at work more effective [2]. During the COVID-19 pandemic which had a high level of uncertainty, each individual had to build positive emotions to increase performance at work even though the conditions were always changing dynamically. According to [1], psychological capital is also directly to positive emotions that leads to higher creativity and broader range of pathways.

This government institution is one of public services that focus on women's empowerment, child protection and government affairs in the field of population control and family planning. Service motto adopted by the organization consist of three principles which called "Smart" is being able to act quickly, precisely, effectively, and efficiently; "Resilient" is being able to survive and recover quickly in difficult conditions; and "Partnership" is building networks and working together on the principle of mutual benefit. However, when COVID-19 pandemic occurred the service offered is not worked as well as the service motto that has been set by organization.

To explore more about the issues that occurred, the researcher conducted preliminary interviews with the lower and upper levels to find out the problems that occurred related to declining performance and not achieving targets. The researcher interviewed four employees at upper level and two employees at lower level. Based on the interviews that have been conducted, the problems that have been identified can be categorized into issues related to job satisfaction. The following is the summarize of several identified issue: 
TABLE I: SUMMARY OF ISSUES

\begin{tabular}{cccc}
\multicolumn{4}{c}{ TABLE I: SUMMARY OF ISSUES } \\
\hline \hline No. & Issues & $\begin{array}{c}\text { Number of } \\
\text { Stated }\end{array}$ & $\begin{array}{c}\text { Job Satisfaction by Spector } \\
(1997)\end{array}$ \\
\hline 1 & Social Distancing & 3 & Operating Conditions \\
2 & Job Salary & 2 & Pay \\
3 & Saturated & 2 & Nature of Work \\
4 & Competency & 2 & Co-Workers \\
5 & Limited Employee Availability & 2 & Operating Conditions \\
6 & Coordination & 2 & Communication \\
7 & Budget Limitation & 1 & Operating Conditions \\
8 & Organizational Transparency & 1 & Communication \\
9 & Discipline & 1 & Nature of Work \\
10 & Appreciation & 1 & Contingent Rewards \\
11 & Difficult to Get a Promotion & 1 & Promotion \\
\hline \hline
\end{tabular}

The issues can be determined by using job satisfaction analysis by Spector [3]. The job satisfaction analysis is consisting of nine facets including: pay, promotion, supervision, fringe benefits, contingent rewards, operating conditions, co-workers, nature of work, and communication. The researcher suspects that job satisfaction can be the one of several issues that can affect employee performance. The condition of employee psychological capital can have a positive or negative impact on job satisfaction, so in this research, the researcher will analyze the impact of psychological capital towards job satisfaction.

\section{LITERATURE REVIEW AND RESEARCH HYPOTHESIS}

\section{A. Psychological Capital}

According to [4] define psychological capital as an individual's positive psychological state of development that is characterized by: (1) having confidence (efficacy) to take on and put in the necessary effort to succeed at challenging tasks; (2) making a positive attribution (optimism) about succeeding now and in the future; (3) persevering toward goals and when necessary, redirecting paths to goals (hope) in order to succeed; and (4) when beset by problems and adversity, sustaining and bouncing back and even beyond (resilience) to attain success. The four positive psychological capital capacities of hope, efficacy, resilience and optimism are measurable, open to development and can be managed for more effective work performance [5]. Higher productivity, improved customer service, and higher employee retention would all benefit from psychological capital.

\section{B. Capacities of Psychological Capital}

Psychological capital consists of four capacities which are: self-efficacy, hope, optimism, and resilience. The combination of the four capacities of psychological capital has a much larger impact on employee attitudes, functions, and performance. Here the explanation regarding each dimension of psychological capital.

- Self-Efficacy

The definition of self-efficacy as the "individual's belief in his or her ability to mobilize the motivation, cognitive capital, and courses of action required to complete a task successfully in a given context" [5]. Employees with higher level in self-efficacy believe that they can create their own success and tend to see things as being overcome by using their own capacity and effort [6]. Conversely, employees who have low efficacy believe that it is useless to put effort in overcoming difficult challenges because it allows employees to feel depressed.

- Hope

The definition of hope as the "being a motivational state resulting from the interaction of three determinants, namely goals, agency, and pathways" [5]. According to [7] hope is the confidence in one's ability to initiate and maintain actions, as well as to devise paths to achieve goals. Employees who have a higher degree of optimism believe in their own ability to build their own success [6]. High hope allows employees to take advantage of planning according to their situation because they can estimate obstacles to achieving goals and can identify several alternative actions to achieve their goals, with the result that improve employee performance.

\section{- Optimism}

The definition of optimism as the "a positive explanatory style that attributes positive events to internal, permanent and pervasive causes, and negative events to external, temporary and situation-specific ones" [1]. Making realistic assumptions and having optimistic expectations for future events are also manifestations of optimism. Employees who are optimistic tend to have a good experience. As a result, adversity is not always viewed as a failure, but rather as an opportunity to develop and succeed, also to get a chance to see the future [5].

- Resilience

The definition of resilience as the "developable capacity to rebound or bounce back from adversity, conflict, failure, or even positive events, progress and increase responsibility" [1]. Resilience is one's ability to respond to difficult circumstances; therefore, it is linked to method rather than outcome [8]. The common characteristics of resilient people are (a) a firm acceptance of reality, (b) a strong conviction, often supported by deeply held beliefs, that life has meaning, and (c) an uncanny capacity to improvise and adapt to significant change [5].

\section{Measurement of Psychological Capital}

In this research, psychological capital was measured using the measurement reference made by [9]. In measuring psychological capital, a questionnaire was designed to assess every aspect of psychological capital consisting of hope, selfefficacy, resilience, and optimism. This questionnaire is known as the Psychological Capital Questionnaire (PCQ). PCQ has 24 statement items in total with 6 items have been adapted from each aspect of psychological capital. This series 
of questionnaires is known as PCQ-24. However, in order to increase efficiency, [9] simplified the 24 statement items into 12 statement items, known as PCQ-12. It consists of 4 items for hope, 3 items for self-efficacy, 3 items for resilience, and 2 items for optimism. In carrying out psychological capital measurements, the researcher will use PCQ-24 with the aim of obtaining detailed and reliable measurements.

\section{Job Satisfaction}

According to [10] job satisfaction is described as "feeling satisfied," "fulfilling needs," and "working with complete desire," and it describes how people feel about their jobs. In the public sector, job satisfaction is characterized as the alignment of needs, personal values, and subsequent work experiences [11]. Job satisfaction has an effect on employee absenteeism, turnover, and psychological distress [11]. The higher the level of job satisfaction, the more motivated workers are to work, which helps improve efficiency and achieve organizational goals. Otherwise, the lower the level of job satisfaction, the less motivated employees are, and therefore the less likely they are to achieve organizational goals [11]. There are nine facets job satisfaction by [3] uses to identify and improve employee satisfaction which consists of pay, promotion, supervision, fringe benefits, contingent rewards, operating conditions, co-workers, nature of work, and communication.

\section{E. Measurement of Job Satisfaction}

In this research, the researcher used the Job Satisfaction Survey (JSS) as a 36-items tool to measure job satisfaction as adapted from [12]. In JSS, the researcher uses nine facets as indicators to measure the level of job satisfaction and each facet is assessed with four items. The nine facets are Pay, Promotion, Supervision, Fringe Benefits, Contingent Rewards (performance-based rewards), Operating Procedures (required rules and procedures), Co-workers, Nature of Work, and Communication. According to [13], JSS is one of the suitable tools to measure the job satisfaction of public service employees, especially like the civil servants (government officials) which analyzed in this research.

\section{F. Research Hypothesis}

According to [14] research hypothesis is a statement of the researcher's expectation or prediction about the relationship between the variables under investigation. The study's goal was to conduct a quantitative and qualitative study into the relationship between psychological capital and job satisfaction in Government Institution. This study also found out the impact of each dimension of psychological capital to job satisfaction. The specific hypothesis in this study is using $\alpha=0.05$, and the details is described as follows:

1. Psychological Capital

$\mathrm{H}_{0}$ : Psychological Capital has no positive effect to Job Satisfaction.

$\mathrm{H}_{1}$ : Psychological Capital has a positive effect to Job Satisfaction.

2. Self-Efficacy Dimension

$\mathrm{H}_{0}$ : Self-Efficacy has no positive effect to Job Satisfaction.

$\mathrm{H}_{1}$ : Self-Efficacy has a positive effect to Job Satisfaction.

3. Hope Dimension

$\mathrm{H}_{0}$ : Hope has no positive effect to Job Satisfaction.
$\mathrm{H}_{1}$ : Hope has a positive effect to Job Satisfaction.

4. Resiliency Dimension

$\mathrm{H}_{0}$ : Resiliency has no positive effect to Job Satisfaction.

$\mathrm{H}_{1}$ : Resiliency has a positive effect to Job Satisfaction.

5. Optimism Dimension

$\mathrm{H}_{0}$ : Optimism has no positive effect to Job Satisfaction.

$\mathrm{H}_{1}$ : Optimism has a positive effect to Job Satisfaction.

\section{Research Methodology}

This research focuses on the impact of psychological capital towards on job satisfaction. During the real research journey, all of the knowledge needed to take a specific step is gathered in one spot. The function of research methodology to describe the flow or framework from business issues and data collection (primary and secondary data) to explains how researchers gather data and then continue to the data processing to process the data become the knowledge and help to analyze the issue. Later the business analysis leads to business solution, give recommendation, and create an implementation plan for Government Institution.

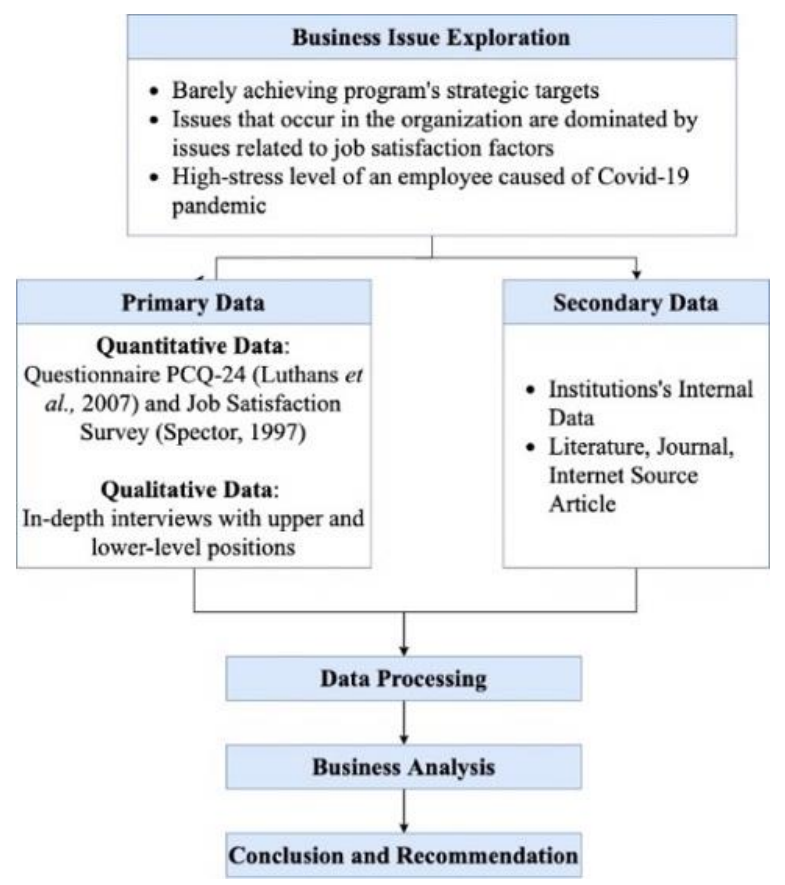

Fig. 1. Research Methodology.

In the first phase, the researcher will elaborate and analyze the current situations of the institution related to employee's job satisfaction and summarize it into three main points of business issues, including, barely achieving program's strategic targets; issues that occur in the organization are dominated by issues related to job satisfaction factors; and high-stress level of an employee caused of the COVID-19 pandemic. In the second phase, the analysis and discussion process will be supported by primary and secondary data. The primary data used is divided into two types of data, including quantitative and qualitative data. Quantitative and qualitative data is used to get a deeper understanding of research mechanism. Quantitative data were obtained using psychological capital questionnaire (PCQ-24) and job satisfaction survey (JSS). Meanwhile, qualitative data 
obtained from interviews with upper and lower-level positions. For the secondary data, the researcher uses institution's internal data, literature, journal, and internet source article to support the analysis and gather relevant information. The next phase is data processing. The data that has been obtained is then processed using statistical tools such as the Method of Successive Interval (MSI) and linier regression. In the fourth phase, the researcher will analyze the results of data processing and interpret conclusions related to the actual performance of psychological capital and job satisfaction. After the researcher knows the actual performance of psychological capital and job satisfaction also what factors have a significant influence, the next phase is the researcher will construct a conclusion and recommendation in the hope of increasing employee job satisfaction.

\section{RESEARCH RESULT}

\section{A. Descriptive Analysis}

Descriptive analysis, in this research, was used to interpret the data that had been collected. The result of this interpretation shows the respondent's perception of the statement in the questionnaire. The researcher will determine how the actual condition of the Psychological Capital and Job Satisfaction variable. A questionnaire consisting of 60 statement items with six alternative answers using a Likert scale. With details on the number of questions for the psychological capital variable (x) there are 24 questions and 36 questions for the job satisfaction variable (y). The respondent of the questionnaire is 52 employees out of 100 employees in total. The questionnaire is recapitulated or tabulated to determine the value of the questionnaire based on the frequency of respondents' answers and the percentage of respondents' answers to each question. The following of interval score criteria for psychological capital and job satisfaction as follows:

TABLE II: INTERVAL SCORE CRITERIA

\begin{tabular}{cccc}
\hline \hline No. & Interval Score $(\%)$ & $\begin{array}{c}\text { Psychological } \\
\text { Capital } \\
\text { Criteria }\end{array}$ & $\begin{array}{c}\text { Job Satisfaction } \\
\text { Criteria }\end{array}$ \\
\hline 1 & $16.6-33.28 \%$ & Very Bad & $\begin{array}{c}\text { Very } \\
\text { Unsatisfied }\end{array}$ \\
2 & $33.29-49.96 \%$ & Bad & Unsatisfied \\
3 & $49.97-66.64 \%$ & Fair Good & Fair Satisfied \\
4 & $66.65-83.32 \%$ & Good & Satisfied \\
5 & $83.33-100 \%$ & Very Good & Very Satisfied \\
\hline \hline
\end{tabular}

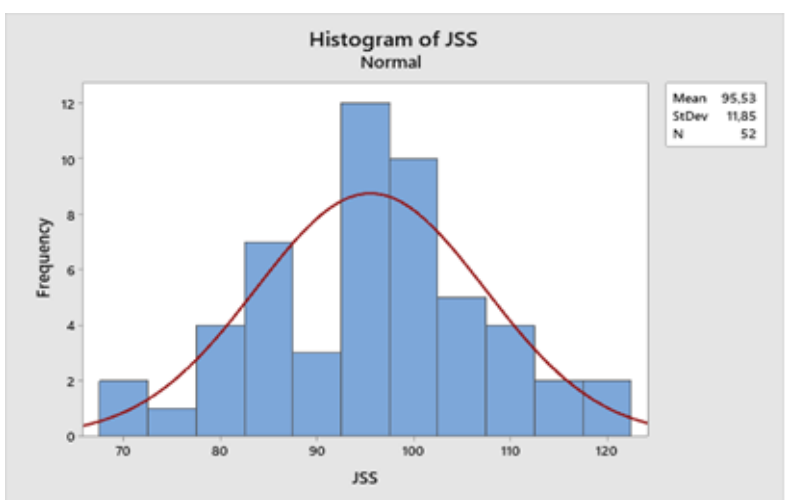

TABLE III: PSYCHOLOGICAL CAPITAL PROFILE

\begin{tabular}{ccccc}
\hline \hline \multirow{2}{*}{ No } & Dimension & $\begin{array}{c}\text { Total } \\
\text { Score }\end{array}$ & $\begin{array}{c}\text { Score } \\
\text { Percentage }\end{array}$ & Status \\
\hline 1 & Self-Efficacy & 1508 & $80,6 \%$ & Good \\
2 & Hope & 1527 & $82 \%$ & Good \\
3 & Resiliency & 1294 & $69 \%$ & Good \\
4 & Optimism & 1496 & $80 \%$ & Good \\
Aggregate Total Score & \multicolumn{2}{c}{5623} & \\
Score Percentage & \multicolumn{2}{c}{$75,1 \%$} & Good \\
Index Maximum Score & & 7488 & \\
Index Minimum Score & & 1248 & \\
Interval Range & & 1248 & \\
\hline \hline
\end{tabular}

TABLE IV: JoB SATISFACTION PROFILE

\begin{tabular}{ccccc}
\hline \hline No & Dimension & $\begin{array}{c}\text { Total } \\
\text { Score }\end{array}$ & $\begin{array}{c}\text { Score } \\
\text { Percenta } \\
\text { ge }\end{array}$ & Status \\
\hline 1 & Pay & 834 & $66,8 \%$ & Satisfied \\
2 & Promotion & 948 & $76 \%$ & Satisfied \\
3 & Supervision & 775 & $62 \%$ & Fair Satisfied \\
4 & Fringe Benefit & 645 & $52 \%$ & Fair Satisfied \\
5 & Contingent Rewards & 687 & $55 \%$ & Fair Satisfied \\
6 & Operation Procedure & 723 & $58 \%$ & Fair Satisfied \\
7 & Coworkers & 786 & $63 \%$ & Fair Satisfied \\
8 & Nature of Work & 914 & $73 \%$ & Satisfied \\
9 & Communication & 658 & $53 \%$ & Fair Satisfied \\
& Aggregate Total Score & \multicolumn{2}{c}{6970} & \\
& Score Percentage & \multicolumn{2}{c}{$62,1 \%$} & Fair Satisfied \\
& Index Maximum Score & \multicolumn{2}{c}{11232} & \\
Index Minimum Score & \multicolumn{2}{c}{1872} & \\
\hline \hline
\end{tabular}

Based on Table III, it is known that the number of each dimension psychological capital that is responded to by the respondents. The combined value of each dimension will be added to the total value of psychological capital. It is known that the value of the aggregate total score: 5623 .

Based Table IV, it is known that the number of each dimension job satisfaction that is responded to by the respondents. The combined value of each factor will be added to the total value of job satisfaction. It is known that the value of the aggregate total score: 6970 .

\section{B. Simple Linear Regression}

Before the researcher conducts simple regression test, the normality of the data must be determined using normality test. The main tests for the assessment of normality using Kolmogorov-Smirnov (K-S) test. The data is in normal distribution if it has a P-Value more than 0.05 . The researcher uses Minitab 19 for the normality test shown at Fig. 2. The data is normally distributed because it has a P-Value score of $>0.150$.

Fig. 2. Normality and P-Plot Chart.

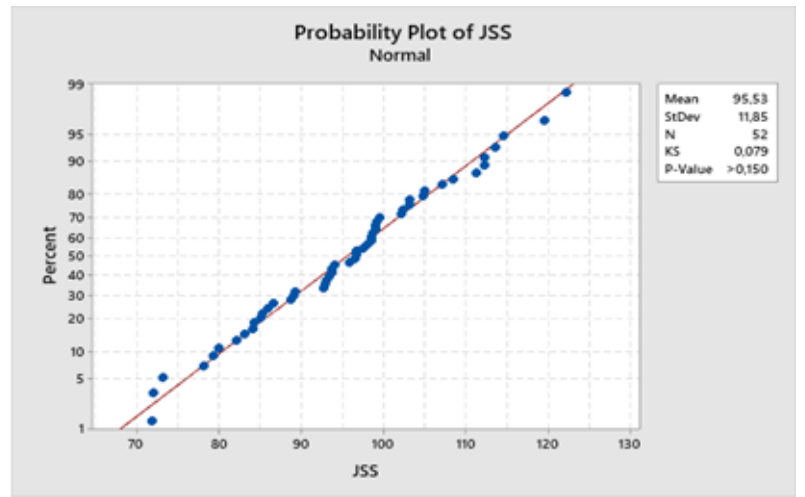


From the histogram chart in Fig. 2, the data is normally distributed because it gives a distribution pattern that deviates to the right. Furthermore, for the P-Plot Chart the data is in normal distribution because the data spreads around the diagonal line and follows the direction of the diagonal line. The following is the result of simple linear regression using Minitab.

TABLE V: SIMPLE LINEAR REGRESSION RESULT

\begin{tabular}{cccccc}
\hline \hline Term & Coef & $\begin{array}{c}\text { SE } \\
\text { Coef }\end{array}$ & $\begin{array}{c}\text { T- } \\
\text { Value }\end{array}$ & $\begin{array}{c}\text { P- } \\
\text { Value }\end{array}$ & VIF \\
\hline Constant & 74,01 & 3,49 & 21,22 & 0,000 & \\
PsyCapt & 0,3109 & 0,0476 & 6,54 & 0,000 & 1,00 \\
\hline \hline
\end{tabular}

Based on the result, the equation of simple regression linear below:

$$
y=74,01+0,3109 x
$$

From the equation above, the relationship between variable $\mathrm{X}$ (independent) and variable $\mathrm{Y}$ (dependent) has a positive correlation. This means that when the value of psychological capital increases, it will have a positive effect on the value of job satisfaction. The coefficient of variable $\mathrm{X}$ represents each increase of one unit of psychological capital will increase job satisfaction by 0.3109 units. The formulation of R Square using Minitab present below:

\begin{tabular}{ccc}
\multicolumn{3}{c}{ TABLE VI: DETERMINATION COEFFICIENT } \\
\hline \hline R-Square & $\begin{array}{c}\text { R-Square } \\
\text { (Adjusted) }\end{array}$ & $\begin{array}{c}\text { R-Square } \\
\text { (Predicted) }\end{array}$ \\
\hline $65 \%$ & $63.48 \%$ & $58.42 \%$ \\
\hline \hline
\end{tabular}

Based on the result, the determination coefficient is $65 \%$. It means that $65 \%$ of the variation in the dependent variable or job satisfaction can be explained by psychological capital, while $35 \%$ is influenced by another variable.

\section{1) T-Test Analysis}

\section{Hypothesis 1}

$\mathrm{H}_{0}$ : Psychological Capital has no positive effect to Job Satisfaction.

$\mathrm{H}_{1}$ : Psychological Capital has a positive effect to Job Satisfaction.

\section{Requirements}

- If $\mathrm{P}-$ Value $<\alpha=0.05$ then $\mathrm{H}_{0}$ in rejection area, meaning $\mathrm{H}_{1}$ is accepted: there is positive effect.

- If $\mathrm{P}-$ Value $>\alpha=0.05$ then $\mathrm{H}_{0}$ in reception area, meaning $\mathrm{H}_{1}$ is rejected: there is no positive effect.

\section{Analysis}

Based on Table V where P-Value of psychological capital is 0,000 lower than $\alpha=0,05$. This mean that $\mathrm{H}_{0}$ is rejected and $\mathrm{H}_{1}$ is accepted. There is a significant influence between psychological capital (x) to job satisfaction (y). So, hypothesis 1 is approved with stated that "Psychological Capital has a positive effect to Job Satisfaction".

\section{Multiple Linear Regression}

To determine the influence of each psychological capital dimension, consist of self-efficacy, hope, resiliency, and optimism to job satisfaction, the researcher use multiple regression analysis. According to [15] multiple regression models describe how a single response variable $\mathrm{Y}$ depends linearly on a number of predictor variables. The researcher conducted a classical assumption test before performing multiple linear regression, consisting of normality test, multicollinearity test and heteroscedasticity test. Goals of the classical assumption test to make the regression model best, linear, unbiased, and estimated.

\section{1) Classical Assumption Test}

\section{Normality Test}

The first step a classical assumption test is the normality test. The normality of the data must be determined using normality test. The main tests for the assessment of normality using Kolmogorov-Smirnov (K-S) test. The data is in normal distribution if it has a Sig. Value more than 0.05. The researcher uses SPSS Software for the normality test shown at Fig. 3. The data is normally distributed because it has a Asymp. Sig (2-tailed) score is 0.145 (shown at appendices).

From the histogram chart in Fig. 3, the data is normally distributed because it gives a distribution pattern that deviates to the right. Furthermore, for the P-Plot Chart the data is in normal distribution because the data spreads around the diagonal line and follows the direction of the diagonal line.
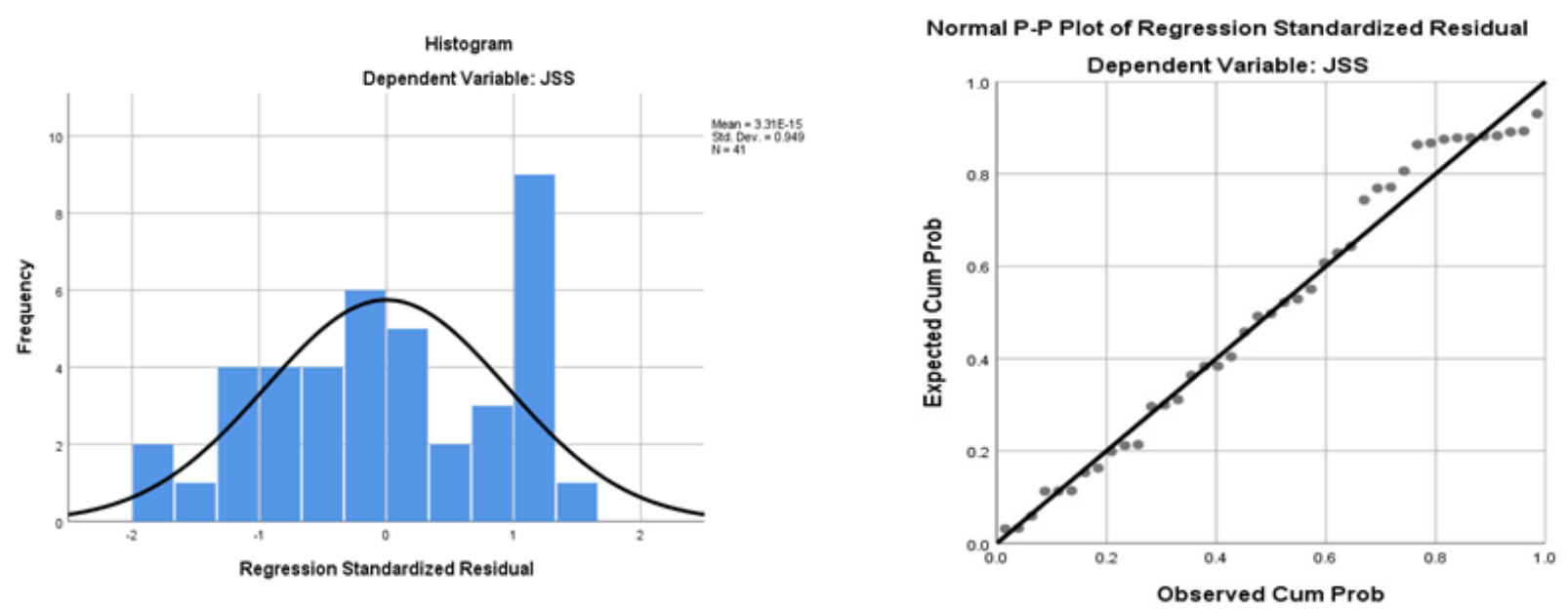

Fig. 3. Normality and P-Plot Chart. 


\section{Multicollinearity Test}

The concept multicollinearity refers to the linear relationships between the independent variables in multiple regression analysis. A good regression model should not have correlation between independent variables (multicollinearity does not occur). It can be seen from the VIF value, there is no VIF value more than 10 . It can be concluded that there is no multicollinearity in the data.

\begin{tabular}{cc}
\multicolumn{2}{c}{ TABLE VII: MULTICOLLINEARITY TEST } \\
\hline \hline \multicolumn{2}{c}{ Collinearity Statistics } \\
\hline Tolerance & VIF \\
0.569 & 1.758 \\
0.458 & 2.182 \\
0.510 & 1.961 \\
0.866 & 1.155 \\
\hline \hline
\end{tabular}

The concept multicollinearity refers to the linear relationships between the independent variables in multiple regression analysis. A good regression model should not have correlation between independent variables (multicollinearity does not occur). It can be seen from the VIF value, there is no VIF value more than 10 . It can be concluded that there is no multicollinearity in the data.

\section{Heteroscedasticity Test}

According to [16] one assumption of multiple regression analysis is homoscedasticity of errors. The heteroscedasticity occurs when the residual variance has an inequality of variance from one observation data to another.

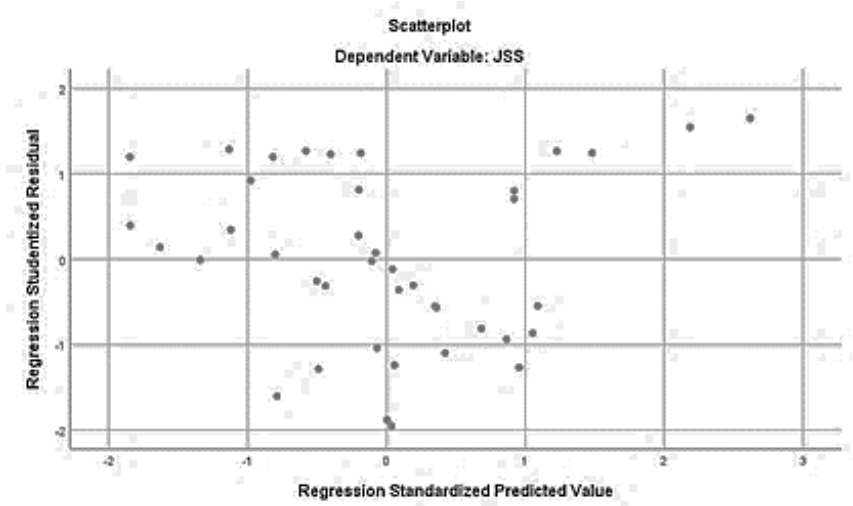

Fig. 4. Scatterplot.

From the scatterplot above shows that the points do not form a single unit (spread). Based on that, the heteroscedasticity test is approved so the data is feasible to be observed for further analysis.

\section{2) Calculation of Multiple Linear Regression}

Table VIII is the result of multiple linear regression.

Based on the result, the equation of simple regression linear below:

$$
\begin{aligned}
& y=60.379+0.589 x 1+0.415 \times 2+0.870 \times 3+ \\
& 0.261 \times 4
\end{aligned}
$$

TABLE VIII: MULTIPLE LINEAR REGRESSION RESULT

\begin{tabular}{ccc}
\hline \hline Variable & $\begin{array}{c}\text { Regression } \\
\text { Coefficient }\end{array}$ & $\begin{array}{c}\text { Std. } \\
\text { Error }\end{array}$ \\
\hline Constant & 60.379 & 6.210 \\
X1 & 0.589 & 0.270 \\
X2 & 0.415 & 0.362 \\
X3 & 0.870 & 0.299 \\
X4 & 0.261 & 0.279 \\
\hline \hline
\end{tabular}

From the equation above, the relationship between variable job satisfaction and variable each dimension of psychological capital has a positive correlation. This means that when the value of psychological capital increases, it will have a positive effect on the value of job satisfaction. The value of dependent variable is 60.379 . The detail value of each dimension described below:

- The coefficient of variable self-efficacy (X1) is positive and represents each increase of one unit of psychological capital will increase variable job satisfaction (y) by 0.589 units.

- The coefficient of variable hope (X2) is positive and represents each increase of one unit of psychological capital will increase variable job satisfaction (y) by 0.415 units.

- The coefficient of variable resiliency (X3) is positive and represents each increase of one unit of psychological capital will increase variable job satisfaction (y) by 0.870 units.

- The coefficient of variable optimism (X4) is positive and represents each increase of one unit of psychological capital will increase variable job satisfaction (y) by 0.261 units.

3) Determination Coefficient

The following is the formulation of R Square:

\begin{tabular}{cccc} 
& \multicolumn{3}{c}{ TABLE IX: DETERMINATION COEFFICIENT } \\
\hline \hline Model & $\mathrm{R}$ & R-Square & Adjusted R-Square \\
\hline 1 & 0.792 & 0.627 & 0.586 \\
\hline \hline
\end{tabular}

Determination Coefficient $=\mathrm{R}^{2} \times 100 \%$

$$
\begin{aligned}
& =62.7 \% \times 100 \% \\
& =62.7 \%
\end{aligned}
$$

Based on the result and equation, the determination coefficient is $62.7 \%$. It means that $62.7 \%$ of the variation in the dependent variable or job satisfaction can be explained by each dimension of psychological capital which consists of self-efficacy (x1), hope (x2), resiliency (x3), and optimism (x4) while $37.3 \%$ is influenced by another variable.

\section{4) Partial Correlation Analysis}

In this research, partial correlation analysis is used to determine how influential each independent variable (each dimension of psychological capital) to dependent variable

\begin{tabular}{|c|c|c|c|c|}
\hline \multirow{3}{*}{ Variable } & Standardized Coefficient & Correlations & The Influence & The Influence Partially \\
\hline & Beta & Zero-Order & Partially & $(\%)$ \\
\hline & [a] & [b] & {$[\mathrm{c}=\mathrm{a} \times \mathrm{b}]$} & {$[\mathrm{d}=\mathrm{c} \times 100 \%]$} \\
\hline $\mathrm{X} 1$ & 0.294 & 0.661 & 0.194 & $19.4 \%$ \\
\hline $\mathrm{X} 2$ & 0.172 & 0.663 & 0.114 & $11.4 \%$ \\
\hline $\mathrm{X} 3$ & 0.415 & 0.705 & 0.292 & $29.2 \%$ \\
\hline $\mathrm{X} 4$ & 0.102 & 0.273 & 0.027 & $2.7 \%$ \\
\hline \multicolumn{3}{|c|}{ Total Influence } & 0.627 & $62.7 \%$ \\
\hline
\end{tabular}
(job satisfaction). The following is the processing result of partial correlation analysis:

TABLE X: PARTIAL CORRELATION 
From the table above, the influence of optimism (x4) is $2.7 \%$ which is the smallest percentage compared to other dimensions of psychological capital. The influence of resiliency ( $\mathrm{x} 3$ ) is $29.2 \%$ which is the largest percentage compared to other dimensions of psychological capital. The influence of self-efficacy (x1) is $19.4 \%$ and for hope (x2) is $11.4 \%$. The total influence of each dimension psychological capital is $62.7 \%$ while $37.3 \%$ is influenced by another variable beside each dimension.

\section{T-Test Analysis}

\section{1) Hypothesis 2}

$\mathrm{H}_{0}$ : Self-Efficacy has no positive effect to Job Satisfaction $\mathrm{H}_{1}$ : Self-Efficacy has a positive effect to Job Satisfaction Requirements

- If $\mathrm{P}-$ Value $<\alpha=0.05$ then $\mathrm{H}_{0}$ in rejection area, meaning $\mathrm{H}_{1}$ is accepted: there is positive effect

- If $\mathrm{P}-\mathrm{V}$ alue $>\alpha=0.05$ then $\mathrm{H}_{0}$ in reception area, meaning $\mathrm{H}_{1}$ is rejected: there is no positive effect

Analysis

See from the summary table, P-Value (Sig.) of selfefficacy is 0,036 lower than $\alpha=0,05$. This mean that $\mathrm{H}_{0}$ is rejected and $\mathrm{H}_{1}$ is accepted. There is a significant influence between self-efficacy dimension (x1) to job satisfaction (y). So, the hypothesis 2 is approved with stated that "SelfEfficacy has a positive effect to Job Satisfaction".

\section{2) Hypothesis 3}

$\mathrm{H}_{0}$ : Hope has no positive effect to Job Satisfaction

$\mathrm{H}_{1}$ : Hope has a positive effect to Job Satisfaction Requirements

- If $\mathrm{P}-$ Value $<\alpha=0.05$ then $\mathrm{H}_{0}$ in rejection area, meaning $\mathrm{H}_{1}$ is accepted: there is positive effect

- If $\mathrm{P}-$ Value $>\alpha=0.05$ then $\mathrm{H}_{0}$ in reception area, meaning $\mathrm{H} 1$ is rejected: there is no positive effect

\section{Analysis}

See from the summary table, P-Value (Sig.) of hope is 0,259 higher than $\alpha=0,05$. This mean that $\mathrm{H}_{0}$ is accepted and $\mathrm{H}_{1}$ is rejected. There is a no significant influence between hope dimension ( $\mathrm{x} 2$ ) to job satisfaction (y). So, the hypothesis 3 is not approved with stated that "Hope has no positive effect to Job Satisfaction".

\section{3) Hypothesis 4}

$\mathrm{H}_{0}$ : Resiliency has no positive effect to Job Satisfaction

$\mathrm{H}_{1}$ : Resiliency has a positive effect to Job Satisfaction Requirements

- If $\mathrm{P}-$ Value $<\alpha=0.05$ then $\mathrm{H}_{0}$ in rejection area, meaning $\mathrm{H}_{1}$ is accepted: there is positive effect

- If $\mathrm{P}$-Value $>\alpha=0.05$ then $\mathrm{H}_{0}$ in reception area, meaning $\mathrm{H}_{1}$ is rejected: there is no positive effect

Analysis

See from the summary table, P-Value (Sig.) of selfefficacy is 0,006 lower than $\alpha=0,05$. This mean that $\mathrm{H}_{0}$ is rejected and $\mathrm{H}_{1}$ is accepted. There is a significant influence between resiliency dimension (x3) to job satisfaction (y). So, the hypothesis 4 is approved with stated that "Resiliency has a positive effect to Job Satisfaction".

\section{4) Hypothesis 5}

$\mathrm{H}_{0}$ : Optimism has no positive effect to Job Satisfaction $\mathrm{H}_{1}$ : Optimism has a positive effect to Job Satisfaction

\section{Requirements}

- If P-Value $<\alpha=0.05$ then $\mathrm{H}_{0}$ in rejection area, meaning $\mathrm{H}_{1}$ is accepted: there is positive effect

- If $\mathrm{P}-$ Value $>\alpha=0.05$ then $\mathrm{H}_{0}$ in reception area, meaning $\mathrm{H}_{1}$ is rejected: there is no positive effect

Analysis

See from the summary table, P-Value (Sig.) of selfefficacy is 0,355 higher than $\alpha=0,05$. This mean that $\mathrm{H}_{0}$ is accepted and $\mathrm{H}_{1}$ is rejected. There is a no significant influence between optimism dimension ( $\mathrm{x} 4$ ) to job satisfaction (y). So, the hypothesis 5 is not approved with stated that "Optimism has no positive effect to Job Satisfaction".

\section{CONCLUSION AND RECOMMENDATION}

\section{A. Conclusion}

By conducting the descriptive analysis, it is known the condition of psychological capital and job satisfaction at the government institution during COVID-19 pandemic. From the results of the descriptive analysis, the psychological capital profile of employees is Good. Overall dimensions have the same "Good" category. From all dimensions of psychological capital, the smallest percent value is resilience with a percentage of $69 \%$. For the dimensions of hope, selfefficacy, and optimism the values are above $80 \%$. The profile of job satisfaction is Fair Satisfied. From all variables of job satisfaction, there are six variables that are categorized as Fair Satisfied; consist of supervision, fringe benefit, contingent rewards, operation procedure, co-workers, and communication. In addition, the variables of pay, promotion, and nature of work are categorized as Satisfied.

By conducting the regression analysis, there are two measurements that have been done: the influence of psychological capital towards job satisfaction and the influence of each dimension of psychological capital towards job satisfaction.

By conducting simple linear regression, the influence of psychological capital towards job satisfaction has been done. The method use is coefficient regression, determination coefficient and T-Test analysis. The first hypothesis is accepted, that psychological capital has a positive effect to job satisfaction.

By conducting multiple linear regression, the influence of each dimension of psychological capital towards job satisfaction has been done. There are four ways to conduct the measurement, consist of coefficient regression, determination coefficient, partial influence analysis and TTest analysis. Coefficient regression analysis shows the relationship between variable each dimension of psychological capital and variable job satisfaction has a positive correlation. The result of determination coefficient is $62.7 \%$. It means that $62.7 \%$ of variation in the dependent variable or job satisfaction can be explained by each dimension of psychological capital, while $37.3 \%$ is influenced by another variable. To find out the influence value of each dimension of psychological capital, a partial influence analysis was carried out. Using beta standardized coefficient with zero-order, self-efficacy gives influence as much $19.4 \%$, hope gives influence as much $11.4 \%$, resiliency gives influence as much $29.2 \%$ and optimism gives influence 
as much $2.7 \%$. For T-Test shows that the hypothesis regarding to the dimensions of psychological capital; selfefficacy and resilience have positive significance towards job satisfaction are accepted because P-Value $<\alpha$. Remaining dimensions; hypothesis for hope and optimism are not accepted because P-Value $>\alpha$, so hope and optimism have no positive significance towards job satisfaction.

\section{B. Recommendation}

The researcher recommends for the government institution by managing psychological capital to increase job satisfaction using the psychological capital intervention. According to [9] psychological capital development interventions usually last 2-3 hours, the development approach for each of the four psychological dimensions consisting of hope, self-efficacy, resilience, and optimism are synergistically integrated and adapted to a particular workplace context. The objective of the psychological capital intervention, it is expected when employees have a high level of psychological capital; they have a positive mindset, healthy soul, ready to go extra-miles and encourage employees to always work with pleasure, therefore the results will be extraordinary, and the process is dominated by positive emotions.

\section{REFERENCES}

[1] F. Luthans and C. M. Youssef-Morgan, "Psychological Capital: An Evidence-Based Positive Approach," Аnnu. Rev. Organ. Psychol. Organ. Behav., vol. 4, pp. 339-366, 2017, doi: 10.1146/annurevorgpsych-032516-113324.

[2] F. Luthans and C. M. Youssef-Morgan, "Human, social, and now positive psychological capital management: investing in people for competitive advantage," Organ. Dyn., vol. 33, no. 2, pp. 143-160, 2004, doi: 10.1016/j.orgdyn.2004.01.003.

[3] P. . Spector, Job Satisfaction: Application, Assessment, causes and consequences. New York: Harper \& Row, 1997.

[4] F. Luthans, C. Youssef-Morgan, and B. J. Avolio, Psychological Capital and Beyond. New York: Oxford Univ. Press, 2015.

[5] F. Luthans, K. W. Luthans, and B. C. Luthans, "Positive psychological capital: Beyond human and social capital," Bus. Horiz., vol. 47, no. 1, pp. 45-50, 2004, doi: 10.1016/j.bushor.2003.11.007.

[6] J. B. Avey, R. Reichard, F. Luthans, and K. Mhatre, "Meta-analysis of the impact of positive psychological capital on employee attitudes, behaviors, and performance," Hum. Resour. Dev. Q., vol. 22, no. 2, pp. 127-152, 2011, doi: 10.1002/hrdq.20070.

[7] C. R. Snyder, S. C. Sympson, F. C. Ybasco, T. F. Borders, M. A. Babyak, and R. L. Higgins, "Development and Validation of the State Hope Scale,” J. Pers. Soc. Psychol., vol. 70, no. 2, pp. 321-335, 1996, doi: 10.1037/0022-3514.70.2.321.

[8] H. Yildiz, "The Interactive Effect of Positive Psychological Capital and Organizational Trust on Organizational Citizenship Behavior," SAGE
Open, vol. 9, no. 3, 2019, doi: 10.1177/2158244019862661.

[9] F. Luthans, B. J. Avolio, J. B. Avey, and S. M. Norman, "DigitalCommons@ University of Nebraska - Lincoln Positive Psychological Capital: Measurement and Relationship with Performance and Satisfaction Positive Psychological Capital: Measurement and Relationship with Performance and Satisfaction,' Pers. Psychol., vol. 60, pp. 541-572, 2007.

[10] Y. Alamrew, H. Belay, and A. D. Shishigu, "The Effect of Governance on Employees' Job Satisfaction, Intention to Leave and Task Performance (A Case of University of Gondar)," Res. J. Commer. Behav. Sci., vol. 6, pp. 1-6, 2016.

[11] H. A. Hijazi, "The Impact of Applying Good Governance Principles on Job Satisfaction among Public Sector Employees in Jordan," Open J. Bus. Manag., vol. 09, no. 01, pp. 1-31, 2021, doi 10.4236/ojbm.2021.91001.

[12] P. . Spector, "Measurement of human service staff satisfaction: Development of the Job Satisfaction Survey," Am. J. Community Psychol., vol. 13, no. 6, pp. 693-713, 1985, doi: https://doi.org/10.1007/BF00929796.

[13] M. S. Jex and W. . Britt, Organizational Psychology: a scientistpractitioner approach, 2nd ed. New Jersey: John Wiley \& Sons, inc, 2008.

[14] K. Anupama, "Hypothesis Types and Research," Int. J. Nurs. Sci. Pract. Res., no. August, 2018, doi: 10.37628/ijnspr.v4i2.812.

[15] M. Bremer, "Multiple Linear Regression," 2012.

[16] A. Klein, C. Gerhard, R. Büchner, S. Diestel, and K. SchermellehEngel, "The Detection of Heteroscedasticity in Regression Models for Psychological Data," Psychol. Test Assess. Model., vol. 58, no. 4, p. $567,2016$.

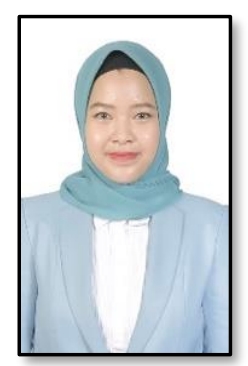

Yumna Sabila was born on February $22^{\text {nd }}$, 1998, in Serang. Graduate from Industrial Engineering at Telkom University, Bandung in 2015. She pursued a Master of Business Administration degree at Bandung Institute Technology (ITB) focusing on People Knowledge Management. She is interested to human capital management, sustainability, and risk management. She has been certified as Certified Human Resource Officer by Badan Nasional Sertifikasi Profesi (BNSP) Indonesia.

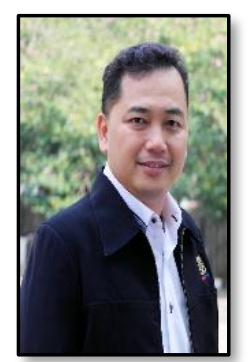

Hary Febriansyah completed his doctoral program at Innsbruck University School of Management, Austria in 2013. His expertise in research is employee engagement, human capital management and knowledge management. Currently, he is an assistant professor at SBM-ITB. Also, he is Director of Centre of Knowledge for Business Competitiveness in SBM-ITB (since 2016) and the Vice President for Program on Knowledge Management Society Indonesia (KMSI). 